\title{
INTERVENCIÓN DEL ESTADO COLOMBIANO EN EL MERCADO DE VALORES
}

\section{Camilo E. Quiñónez Avendaño}

Doctorando en Derecho (c) Universidad Externado de Colombia; Magíster en Derecho Económico, Universidad Externado de Colombia; Especialista en Derecho Comercial Universidad Autónoma de Bucaramanga - Universidad Externado de Colombia; Especialista en Derecho Empresarial Universidad Autónoma de Bucaramanga UNAB. Docente-Investigador -Universidad Autónoma de Bucaramanga. E-mail: camiloq2@gmail.com

\section{Resumen}

El Estado colombiano interviene en el mercado de valores por mandato constitucional. La intervención está orientada a cumplir fines trazados en la ley marco que no responden a razones económicas ni financieras. El presente artículo consta de tres partes: En primer lugar se presentan las razones que justifican la intervención del Estado, en segundo se describe el mercado objeto de intervención, en tercer lugar se presentan los rasgos distintivos o propiedades del modelo de intervención adoptado en Colombia, para finalmente sostener que la intervención estatal no está orientada por la rigidez de la economía neoclásica a corregir fallas de mercado ni por razones financieras relacionadas con extinguir o administrar riesgos presentes en el mercado.

\section{Palabras clave}

Mercado de valores, valores, emisores, inversionistas, intermediarios, fallas del mercado, riesgos, sistema integral de información del mercado de valores, regulación, supervisión

\begin{abstract}
The Colombian government has the faculty to intervene in the stock market by constitutional mandate. The intervention is designed to fulfill the purposes outlined within a legal framework that does not respect to economic of financial reasons. This article consists of three parts: First, we present the reason for state intervention in the market, second describes the target market intervention, and in third place, the distinctive features or properties of the intervention model adopted in Colombia, and finally argue that state intervention is guided by the rigidity of neoclassical economics to correct market failures or for financial reasons related to termination or manage risks in the market.
\end{abstract}

\section{Key Words}

Securities market, securities, issuers, investors, brokers, market failures, risks, integrated information system of the stock market, regulation, supervision. 

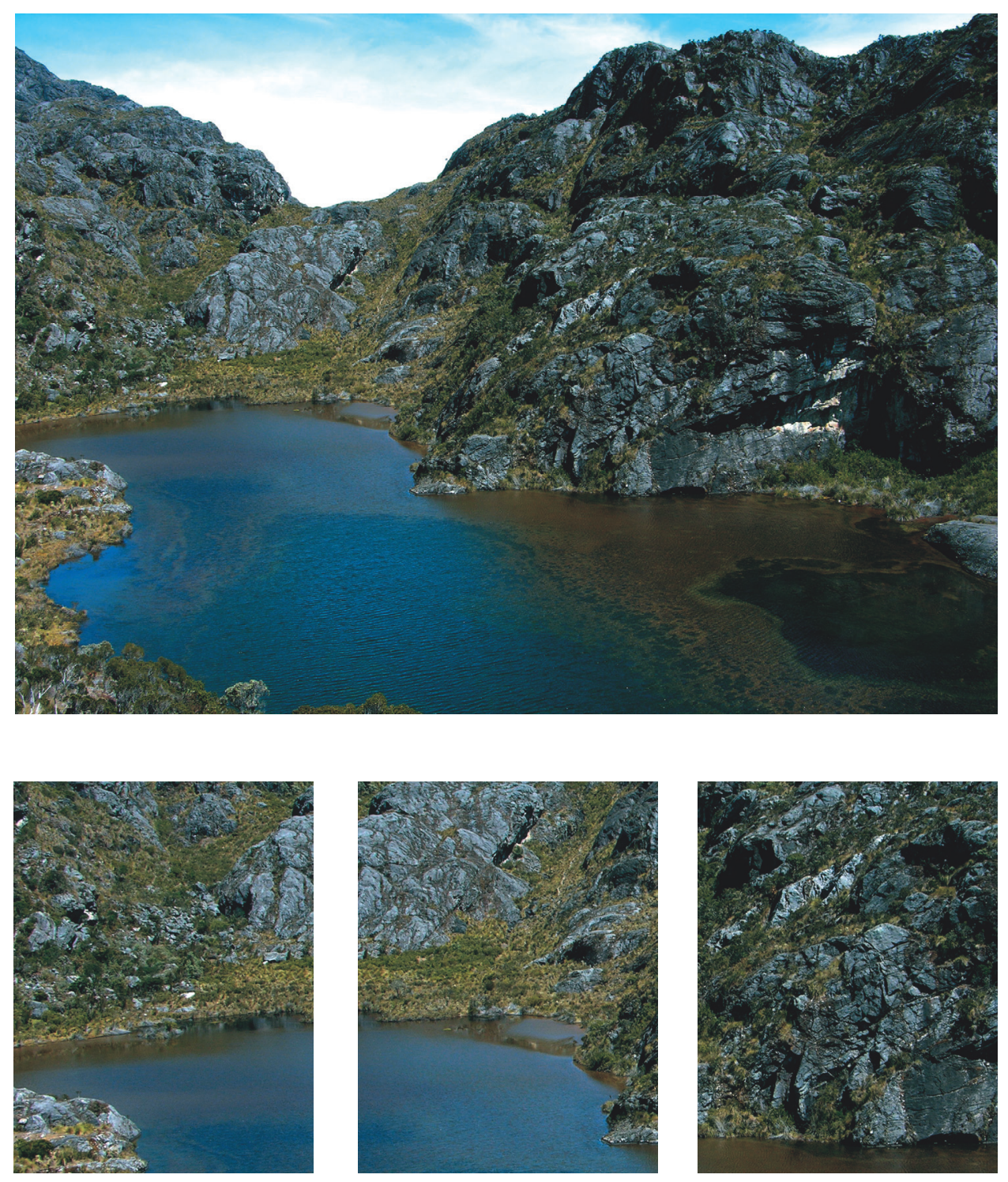

Camino a la "Laguna Colorada" 


\section{INTERVENCIÓN DEL ESTADO COLOMBIANO EN EL MERCADO DE VALORES*}

Camilo E. Quiñónez Avendaño

\section{Introducción}

Los mercados de valores no son ajenos al debate teórico entre quienes abogan por reducir al mínimo la intervención estatal en fenómenos económicos y quienes sostienen que el Estado debe asumir un papel importante para corregir las carencias, fallas o limitaciones del mercado y para buscar un grado más alto de justicia social. Las ideas expresadas en este artículo están en el segundo grupo. El Estado colombiano interviene en el mercado de valores.

El supuesto teórico de la intervención es:

"aún cuando los mercados están en el centro de nuestra economía, si los dejamos funcionar solos, no siempre funcionan como debieran; porque no son ninguna panacea y porque el gobierno siempre será un aliado relevante para ellos" (Stiglitz, 2003, 16)

En este escrito se analiza la forma como el Estado colombiano interviene en el mercado de valores. Para tal fin se presenta un $\mathrm{m}$ arco teórico para el análisis que responde a las razones que justifican la intervención estatal; se describe el mercado objeto de intervención y se ofrece una reseña de las características del modelo de intervención.

\section{Justificación de la intervención del Estado en el mercado de valores}

El marco referencial que se presenta en este apartado suministra fundamentación teórica para responder al por qué y para qué la intervención estatal en un mercado que tradicionalmente ha sido considerado como perfecto y eficiente. La intervención tiene justificación económica, jurídica y financiera:

El artículo, reflexiona sobre la intervención estatal en el mercado de valores. El texto se realiza en el marco del desarrollo del doctorado en Derecho realizado por el autor, en la Universidad Externado de Colombia. 


\section{Económica}

Desde el punto de vista económico los mercados de valores fueron ejemplo de mercados perfectos y eficientes porque cumplían con las siguientes características (Cachón, 1992, 21):

- Mercado libre, donde el precio es fruto de la negociación directa entre los operadores o sus intermediarios

- Mercado de competencia: con amplio número de demandantes y oferentes, de forma que no existen situaciones de monopolio u oligopolio

- Mercado de producto homogéneo: los productos negociados pertenecientes a la misma emisión son iguales entre sí, lo que facilita su fácil intercambio;

- Mercado transparente: existe información amplia sobre los valores negociados en ese mercado, al alcance de todos los intermediarios e inversionistas en condiciones de igualdad, con independencia de la igual o desigual interpretación que los operadores hagan de dicha información.

- Mercado profundo: en él tienen lugar un número elevado de operaciones, de forma que el precio es representativo del total de la oferta y la demanda existente y no de la actuación individual de un operador.

- El mercado se considera eficiente porque la actuación de los operadores, en busca cada uno del máximo beneficio con acceso igualitario a la información, hace que el precio de un valor sea representativo del total de la información pública disponible en el mercado.

El auge de los negocios y el desarrollo del mercado mostraron que no hay mercados perfectos. En adelante no se podía guiar a los mercados con el postulado

"Todo hombre, con tal que no viole las leyes de la justicia, debe quedar en perfecta libertad para perseguir su propio interés como le plazca, dirigir su actividad e invirtir sus capitales en concurrencia con cualquier otro individuo o categoría de personas" (Smith, 1997,612).

Al reconocer imperfecciones en el mercado la presencia del Estado se hizo necesaria ya para remediar fallas del mercado o para procurar un orden de mercado.

\section{Intervención estatal para remediar fallas del mercado ${ }^{1}$}

La intervención estatal en el mercado se justifica en el hecho que todos los mercados fallan. Las fallas del mercado son el monopolio o comportamiento anticompetitivo, la conducta impropia en el mercado, la asimetría de información y la inestabilidad sistémica.

1 Esta razón tiene como referente un postulado de la Escuela Neoclásica en economía. Su exponente es León Walras. 
El funcionamiento natural de un mercado se altera sobre la base de que el costo de la falla sea mayor que cualesquiera costos que imponga la intervención estatal. Bajo esta línea argumentativa, el Estado debe adelantar un proceso continuo de evaluación de los costos y beneficios de la regulación (Carmichael y Pomerleano, 2005, 24).

El papel del Estado es impedir que los agentes marchen sin control en el mercado y corregir las fallas que puedan impedir la eficiencia del modelo de mercado. Las fallas en el mercado de valores están asociadas fundamentalmente con asimetría de información.

La asimetría de información se produce cuando el emisor dispone de información relevante que no ha sido objeto de publicidad y puede ser conocida de forma privada por algunos inversionistas. Mientras la información no sea objeto de publicidad, se crea un problema de selección adversa a tal punto que se impone un riesgo de información sobre los inversionistas. Las pérdidas de los desinformados van a ser igual a las ganancias de los informados, por lo que aquellos se protegerán del riesgo de información al pedir mayores responsabilidades ex ante (García, 2002, 5).

La selección adversa es un tipo de falla del mercado provocado por la información asimétrica, se presenta cuando una de las partes involucradas en la operación tiene más información acerca del valor sobre el cual se realiza la transacción. Incide en la formación de precios y en la toma de decisiones del inversionista, quien va a estar más expuesto frente al incumplimiento del emisor (Pindyck, 2003,631).

La función reguladora se orienta a asegurar revelación cabal y oportuna de todo el material informativo que los inversionistas necesitan para tomar decisiones y a proteger a los participantes en el mercado de la conducta anticompetitiva y de prácticas inescrupulosas.

Bajo esta perspectiva el interés del regulador se orienta a determinar qué y cómo revelar. Respecto a qué revelar los sistemas reguladores centran interés en la materialidad del estándar de información, el cual exige a las firmas revelar toda la información que sea material para las decisiones de inversión..

La intervención que adopta esta modalidad se conoce como "regulación de integridad del mercado" (Carmichael y Pomerleano, 2005, 25). La intervención está destinada a enfrentar la conducta injusta o fraudulenta y la publicación inadecuada de información sobre la cual han de basarse las decisiones de inversión y a promover la confianza en la eficiencia y la justicia de los mercados.

Tiene como finalidad proteger a los participantes del mercado de prácticas comerciales fraudulentas o injustas y mediante dicha protección busca promover la confianza en la eficiencia y la justicia de los mercados. 


\section{Intervención para mantener el orden del mercado ${ }^{2}$}

El Estado tiene la obligación de brindar los medios para lograr la coordinación derivada de los mercados. Bajo este planteamiento el orden del mercado no se altera, se trata de un orden espontáneo frente al cual el Estado debe proveer el procedimiento y las condiciones necesarias para mantenerlo.

El papel de la regulación es determinar el conjunto de procedimientos que permitan mantener el orden económico derivado de la libre competencia y de la autonomía de la voluntad privada.

El gobierno debe estar presto a amparar la buena marcha del sistema, absteniéndose, por un lado, de actuaciones que puedan desarticularlo y protegiéndolo, por otro, contra posibles ataques de terceros (Hayek, 2006, 433).

\section{Jurídica}

Desde el punto de vista jurídico se justifica la intervención por razones de interés público ${ }^{3}$. Corresponde al Estado determinar si la actividad tiene repercusión pública capaz de beneficiar a terceros y si ella es útil a la comunidad para calificarla como de interés público, intervenir en ella y someterla al poder de policía (Zegarra, 2005, 176). La intervención no está orientada a restaurar o promover la competencia en el mercado.

Los Estados que utilizan este modelo califican, en la Constitución Política o en su normativa interna, como de interés público las actividades financiera, aseguradora, bursátil y cualquier actividad relacionada con la captación, el manejo, y el aprovechamiento de recursos captados del público. Con este enfoque se plantea la fórmula "interés público igual a control público", lo que supone un sometimiento de los particulares a una serie de deberes impuestos por el Estado.

\section{Financiera}

En la teoría financiera la intervención del Estado en el mercado se concibe como un instrumento para la gestión del riesgo. ${ }^{4}$

2 Modelo tomado de Escuela Austriaca. Representantes Carl Menger, Ludwing Von Mises, Friederich Hayek

3 Modelo norteamericano construido a partir de sentencia proferida en el caso Munn- Illinois de 1876. En esta sentencia se resuelve el conflicto suscitado por la aplicación de la ley del Estado de Illinois que regulaba el almacenamiento de grano a una empresa llamada Munn and Scout, la cual había aplicado unos precios superiores a los permitidos por la ley del Estado.

4 Conforme al Diccionario de la Real Academia de la Lengua española riesgo es la "contingencia o proximidad de un daño". En la teoría financiera se entiende por riesgo aquella condición en la que existe una posibilidad de desviarse del resultado esperado o deseado; una situación potencial de daño que puede producirse o no. 
Los riesgos presentes en el mercado de valores son: riesgo de crédito, riesgo de mercado, riesgo de interés, riesgo de liquidez, riesgo país, riesgo de transferencia, operativo y legal.

El riesgo de crédito es la posibilidad de sufrir una pérdida originada por el incumplimiento de las obligaciones contractuales de pago. El incumplimiento puede tener origen en distintas circunstancias: un retroceso en la solvencia de los agentes prestatarios, problemas de liquidez, pérdidas continuadas, disminución de ingresos, reducción de los niveles de patrimonio, aumento en las tasas de interés, desempleo o ausencia de voluntad de pago.

Con la expresión riesgo de mercado se describen las posibles pérdidas que pueden producirse en activos financieros originadas por movimientos adversos de los precios de mercado. En esta tipología se incluye el riesgo de interés y el riesgo de cambio. El primero puede producirse por un movimiento en los tipos de interés que se materializa en pérdidas de valor de mercado de activos financieros sensibles al tipo de interés, como los títulos de renta fija (pública y privada) y en general, todos los activos cuyo precio sea sensible a los movimientos de los tipos de interés. El riesgo de cambio se presenta cuando los activos financieros estén expresados en moneda extranjera y el resultado esperado por los agentes no se da por la variación de la tasa de cambio 5 .

Riesgo de liquidez se define como la posibilidad de sufrir pérdidas originadas por la dificultad, total o parcial, de realización de ventas o compras de activos, sin sufrir una modificación sensible de los precios. También se refiere a pérdidas originadas por encontrar dificultades en la financiación necesaria para mantener el volumen de inversión deseado.

Una empresa o un inversionista pueden sufrir una pérdida como consecuencia del contexto económico y político de invertir en un país. Esta tipología de riesgo se conoce como riesgo país. Incluye las medidas tomadas por el poder público, los acontecimientos políticos internos y externos, fenómenos macroeconómicos como inflación, endeudamiento externo, crisis financieras y bancarias.

El riesgo soberano lo asume el acreedor tanto de los Estados como de las empresas garantizadas por ellos, originado por la falta de eficacia de las acciones legales contra el prestatario o último obligado al pago, por razones de soberanía.

El riesgo operativo es la probabilidad de sufrir pérdidas financieras como consecuencia de deficiencias en los sistemas de información en los controles internos por errores en el procesamiento de las operaciones $u$ otros aspectos operativos o tecnológicos. Las transacciones financieras deben ser registradas, almacenadas y contabilizadas y debe hacerse un seguimiento durante su existencia hasta que son canceladas. Cualquier discrepancia entre lo que debe ser y lo que realmente es produce la materialización de riesgo operativo.

5 Tasa de cambio es el valor de una moneda extranjera expresada en unidades de moneda nacional. 
Son manifestaciones de riesgo operativo las fallas en el mercado asociadas con: la incompetencia, el fraude y la habilidad, destreza o experiencia de los sujetos que intervienen en el mercado de valores; ejecución y confirmación de órdenes, registro de una transacción, liquidación de una compraventa, complejidad del producto, modelo de valuación erróneo; fallas en sistemas tecnológicos y errores en sistemas de telecomunicaciones; eventos políticos y aplicación de la normativa vigente en el mercado.

El riesgo legal se presenta por la posibilidad de que existan errores en la formulación, interpretación y aplicación de normas jurídicas y contratos de una manera distinta a la esperada por los agentes del mercado.

\section{Mercado de Valores}

El objeto de intervención del Estado colombiano es el mercado de valores en sus distintas manifestaciones: primario y secundario; de comisionistas, de mediadores y de subastas bursátil o extrabursátil y de renta fija y renta variable.

En sentido amplio, la expresión mercado abarca un conjunto de compradores y vendedores que, por medio de sus interacciones reales o potenciales, determinan el precio de un producto o de un conjunto de productos (Pindyck, 2003, 7).

En Colombia el "mercado de valores" es uno de los componentes del mercado de capitales. Por mercado de capitales se entiende el conjunto de mecanismos a disposición de una economía para cumplir la función básica de asignación y distribución, en el tiempo y en el espacio, de los recursos de capital, los riesgos, el control y la información asociados con el proceso de transferencia del ahorro la inversión ${ }^{6}$.

En el contexto colombiano la expresión "mercado de capitales" incluye el mercado bancario y el no bancario, siendo el no bancario el que corresponde al mercado de valores (mercado de acciones y de renta fija, entre otros).

En el contexto internacional se utiliza la expresión "mercado financiero" para caracterizar la institución en la cual se negocian activos financieros tales como las acciones, bonos, valores materializados en papel o desmaterializados ${ }^{7}$, que representan obligaciones legales sobre algún beneficio futuro que son pagadas por el emisor del activo financiero a favor del inversionista. Una parte transfiere fondos a dichos mercados mediante la compra de activos financieros en poder de otra parte (Madura, 2001, 2).

6 Esta definición está tomada del informe final presentado por la Misión de Estudios del Mercado de Capitales realizada en 1996, contratada por el Ministerio de Hacienda de Colombia y el Banco Mundial.

7 En los activos desmaterializados los derechos no están representados en papeles, tienen un soporte electrónico conocido con el nombre de anotación en cuenta. 
Los mercados financieros reciben distintos nombres según el tipo de obligaciones financieras sobre las cuales se realizan transacciones. Existen "mercados de deuda" y "mercados de acciones"; por el vencimiento de la obligación, se utiliza la expresión "mercado de dinero", para referirse a un mercado financiero para instrumentos de deuda a corto plazo y la expresión "mercado de capitales" financieros con vencimiento a un largo plazo (Fabozzi, 1996, 7).

En mercado primario la negociación de valores tiene lugar entre emisor, que actúa como vendedor e inversionista como comprador. El mercado será secundario cuando los compradores y vendedores son inversionistas que intercambian obligaciones previamente emitidas, a éste también se le conoce como mercado para instrumentos maduros. En el mercado primario se proporcionan fondos al emisor inicial de los valores, mientras que en el secundario el emisor del activo no recibe fondos del comprador, éste es un mercado en el que oferentes y demandantes son inversionistas.

De igual forma, en el contexto internacional se utilizan las expresiones mercados de búsqueda directa, de comisionistas, de mediadores y de subastas (Bodie, 2004,11).

El mercado de búsqueda directa se caracteriza porque compradores y vendedores no hacen uso de intermediarios para realizar una transacción, se buscan directamente lo que implica que no hay necesidad de incurrir en costos financieros para perfeccionarla.

El mercado de comisionistas (broker), supone intermediación, esto es, presencia de sujetos con conocimiento especializado del mercado de los activos financieros que en él se negocian al igual que los criterios de valoración de los mismos, función primordial del comisionista es acercar la oferta y demanda de activos financieros. En sentido común su papel en el mercado es ofrecer servicios de búsqueda tanto a compradores como vendedores.

En el mercado de mediadores (dealer) hay sujetos especializados que compran los activos por su cuenta y luego los venden para conseguir rendimientos. El beneficio del mediador es la diferencia entre el precio de compra y el precio de venta del activo financiero objeto de negociación.

En el mercado de subastas, se evidencia mayor nivel de organización e integración, en el sentido que en él convergen todos los operadores económicos en un solo lugar con el propósito de comprar o vender activos financieros. Los agentes que intervienen no están geográficamente dispersos, cuentan con una localización fija en lugares especializados conocidos como bolsa de valores.

8 Esta definición aplica en el contexto internacional. En Colombia se entiende no solamente el mercado de activos financieros de largo plazo, también comprende el mercado de control, riesgo e información. Al respecto puede consultarse Misión de Estudio del Mercado de Capitales. Informe final. Bogotá, 1996. Ministerio de Hacienda,- Banco Mundial-Fedesarrollo 
Según las transacciones sobre activos financieros se realicen dentro o fuera de una bolsa de valores, las denominaciones del mercado cambian a "mercado bursátil" y "mercado de mostrador o extrabursátil" .

Según la rentabilidad los mercados también son objeto de clasificación. Hay mercados de renta variable y de renta fija. En los mercados de renta variable los inversionistas negocian activos financieros cuya rentabilidad depende de múltiples factores, entre los que se encuentran la evolución de la economía -doméstica y global-, el comportamiento de los emisores y la liquidez en el mercado secundario. El activo financiero por excelencia en este mercado, son las acciones. En el mercado de renta fija los inversionistas tienen claridad respecto al capital invertido y a la rentabilidad esperada.

La expresión mercado de valores incluye los mercados primario y secundario; de comisionistas, de mediadores y de subastas; bursátil y extrabursátil y renta fija y renta variable.

Al mercado de valores acude el emisor de valores ${ }^{10}$, esto es, un sujeto de derechos. El calificativo de emisor de valores sólo se atribuye a las personas jurídicas (con ánimo de lucro o sin él, de naturaleza pública o privada), que crean, emiten y ponen en circulación valores, títulos valores, activos financieros o valores en papel, materializados o desmaterializados, ya de contenido crediticio, reales o de tradición o corporativos o de participación.

La expresión "emisor de valores", se hace extensiva a universalidades jurídicas ${ }^{11}$ -resultantes de titularización de cartera hipotecaria por parte de entidades del sector solidario, asociaciones mutualistas de ahorro y crédito, cooperativas financieras, los fondos de empleados, el Fondo Nacional de Ahorro y cualesquiera otra entidad diferente de los establecimientos de crédito-; fondos o carteras colectivas y patrimonios autónomos, constituidos o no como fondo común mediante un contrato de fiducia, cuya naturaleza no es la de personas jurídicas sino la de patrimonios afectados al cumplimiento de un fin.

El emisor de valores busca poner en el mercado, directamente o a través de sociedades comisionistas de bolsa los valores por ellos emitidos, en busca de recursos monetarios para atender necesidades relacionadas con realizar reestructuraciones corporativas; sustituir pasivos de corto plazo por deudas de largo plazo; invertir en

9 Mercado extrabursátil también es conocido como mercados OTC (Over The Counter) que significa operaciones sobre el mostrador.

10 Esta definición ha sido elaborada por el autor de este artículo con base en el contenido del artículo 1.1.2.2. de la Resolución 400 de 1995 de la Sala General de la Superintendencia de Valores, modificada por el Decreto 3139 de 2006.

11 El artículo 1.1.2.2. de la Resolución 400 de 1995 modificado por el Decreto 3139 de 2006, considera que en Colombia pueden ser emisores de valores las universalidades de que trata la ley 546 de 1999. El artículo 12 de esta ley autoriza a los establecimientos de crédito y a las entidades aquí citadas (descritas en el artículo 1 de la misma ley) para emitir títulos representativos de créditos otorgados para financiar la construcción y la adquisición de vivienda. 
proyectos de expansión, modernización o desarrollo, adquirir maquinaria, tecnología o ampliar la planta productiva, obtener capital de trabajo (compra de insumos, materia prima, pago de servicios, salarios y proveedores, entre otros).

Cuando el emisor es un sujeto de derecho público las necesidades específicas para atender con la emisión de valores pueden estar asociadas con: reestructuración de deuda pública, financiación el gasto público, adquisición de recursos para atender inversiones en infraestructura, controlar variables macroeconómicas y cubrir o atender desequilibrios presupuestales.

El emisor de valores obtendrá del mercado recursos monetarios para atender sus necesidades, en la medida en que logre vender los valores que emita. La expresión valor o valores, sinónimo de activo financiero, se utiliza para mencionar a todo instrumento de naturaleza negociable que haga parte de una emisión, cuando tenga por objeto o efecto la captación de recursos del público, en la cual quedan incluidos las acciones, los bonos, los papeles comerciales, los certificados de depósito de mercancías, cualquier título o derecho resultante de un proceso de titularización, cualquier título representativo de capital de riesgo, los certificados de depósito a término, las aceptaciones bancarias, las cédulas hipotecarias y cualquier título de deuda pública. No incluye las pólizas de seguros y los títulos de capitalización ${ }^{12}$.

La circulación y negociación de valores se hace dentro o fuera de una bolsa de valores. Estas son un centro de negociación de valores, un punto de encuentro entre oferta y demanda de valores, que contribuye al crecimiento y desarrollo del mercado y a canalizar el ahorro hacia la inversión productiva. De igual forma facilitan la movilidad de la riqueza y confieren seguridad jurídica en las transacciones que a través de ellas se realizan (Formariz, 2001, 257).

Los mercados de valores cuyas operaciones se realizan a través de la bolsa de valores (mercado bursátil), dada la organización, especialidad y complejidad de sus operaciones no permiten al emisor y al inversionista acudir directamente a él. Para acceder a ellos es necesario acudir a profesionales dedicados a prestar servicios de inversión, que pueden actuar como comisionistas (broker) o como mediadores (dealer). En cambio, en el mercado de valores que se realiza fuera de la bolsa de valores (mercado extrabursátil u OTC), la presencia de comisionistas o mediadores es definida por el emisor o inversionista.

El inversionista es un agente superavitario que dispone de recursos monetarios y ha decidido orientarlos hacia la inversión en valores o activos financieros. Puede ser persona natural ${ }^{13}$ o jurídica interesada en dar uso productivo a sus recursos de manera eficiente con el fin de obtener rendimientos que incrementen su patrimonio.

En el inversionista persona jurídica se encuentran instituciones que administran

12 El concepto de valor se toma con el alcance previsto en el artículo 2 de la Ley 964 de 2005

13 El Derecho colombiano distingue entre inversionista profesional y cliente inversionista. Estar en una u otra categoría depende de tener o no la experiencia y conocimientos necesarios para comprender, evaluar y gestionar los riesgos inherentes a cualquier decisión de inversión. Puede consultarse el Decreto 1121 de 2005. 
el ahorro de la comunidad que reciben a diferentes títulos (inversión, pensiones, cesantías), para ser invertidos en portafolios de renta fija o variable, conocidos como inversionistas institucionales. Son uno de los pilares de cualquier mercado de capitales tanto por la estabilidad que le transmiten a la demanda de títulos, como por la posibilidad de servir de instrumento para la democratización de la propiedad en el mercado de valores (Martínez, 2004, 9).

En Colombia existen diversos tipos de inversionistas institucionales tales como las compañías de seguros, las sociedades de capitalización, las administradoras de fondos de inversión y los fondos mutuos de inversión, fondos de pensiones y fondos de cesantías ${ }^{14}$ y los fondos o carteras colectivas de inversión.

\section{Características del Modelo de Intervención}

Las características o cualidades de la forma como el Estado colombiano interviene en el mercado de valores se presentan a continuación. Hecha esta labor se analizan en conjunto a la luz de las razones que justifican la intervención.

\section{a. Separación de las facultades de intervención y supervisión}

El Estado colombiano interviene en el mercado de valores mediante la regulación y supervisión. El modelo de intervención parte de calificar la actividad bursátil y cualquier otra relacionada con el manejo, aprovechamiento e inversión de recursos captados del público como de "interés público".

La intervención estatal vía regulación es ejercida de manera exclusiva por el Gobierno nacional mediante la expedición de decretos que deben estar sometidos a las normas generales, objetivos y criterios que el Congreso de la República señale en la ley marco. ${ }^{15}$

Por mandato constitucional, corresponde al Presidente de la República ejercer de acuerdo con la ley, la inspección, vigilancia y control sobre las personas que realicen actividades financiera, bursátil, aseguradora y cualquier otra relacionada con el manejo e inversión de los recursos captados del público. ${ }^{16}$

La supervisión que es inherente a la potestad estatal de defensa y guarda del interés público, ha sido delegada a la Superintendencia Financiera de Colombia. Este organismo tiene como objetivo promover, organizar y desarrollar el mercado de valores colombiano y la protección de los inversionistas, busca lograr información veraz, oportuna, suficiente, controlar el debido funcionamiento del mercado y de

14 La tipología de inversionistas institucionales se ha tomado de los artículos 36 y 38 del Decreto 663 de 1993 Los fondos de pensiones y cesantías pertenecen a esta categoría, no obstante el artículo 3 de este decreto las califica como "sociedades de servicios financieros"

15 Constitución Política Colombia: Artículos 150 numeral 19 letra d; 189 numeral 25

16 Constitución Política de Colombia: artículo 189 numeral 24 
sus instituciones y, en general, verificar el cumplimiento del marco regulatorio. Los objetivos se orientan a asegurar la estabilidad institucional y a evitar que se vulneren derechos de los sujetos que intervienen en el mercado. ${ }^{17}$

Para cumplir con sus funciones la Superintendencia financiera de Colombia ha diseñado su estructura de la siguiente forma: Se han creado dos superintendentes delegados adjuntos uno para la supervisión institucional y otro para la supervisión de riesgos y conductas de mercado.

Del Superintendente delegado adjunto para la supervisión institucional dependen el Superintendente delegado para emisores, portafolios de inversión y otros agentes y el Superintendente delegado para intermediarios de valores y agentes.

Al Superintendente delegado adjunto para supervisión de riesgos y conductas de mercado está adscrito el Superintendente delegado para supervisión de riesgos de mercados e integridad y el Superintendente delegado para riesgos operativos.

\section{b. La intervención estatal en el mercado de valores está orientada por objetivos y criterios señalados en la ley marco del mercado de Valores}

El sistema normativo mediante el cual se materializa la intervención del Estado colombiano en el mercado de valores está orientado por cuatro objetivos que son: proteger los derechos de los inversionistas; promover el desarrollo y la eficiencia del mercado de valores; prevenir y manejar el riesgo sistémico del mercado de valores y preservar el buen funcionamiento, la equidad, la transparencia, la disciplina y la integridad del mercado de valores $y$, en general, la confianza del público en el mismo ${ }^{18}$.

Los objetivos señalados en la ley marco acogen recomendaciones de la Organización Internacional de Comisiones de Valores ${ }^{19}$, quien fijó objetivos y principios que constituyen la base de un sistema efectivo de regulación de los mercados de valores como guía y parámetro para los reguladores hacia una regulación efectiva.

Con base en la protección de los derechos de los inversionistas, el Estado colombiano busca establecer medidas adecuadas de protección a los inversionistas de prácticas engañosas, fraudulentas o de manipulación así como las relacionadas con el uso de información privilegiada.

Con la promoción del desarrollo y la eficiencia del mercado de valores se busca el

17 Mediante Decreto 4327 de 2005 se creó la Superintendencia Financiera de Colombia. Con esta disposición desaparecen las Superintendencias Bancaria y de Valores.

18 Artículo 1 Ley 964 de 2005. Esta es la ley marco del mercado de valores

19 La OICV (IOSCO - (International Organization of Securities Commissions) existe y funciona como un foro de cooperación internacional entre reguladores de los mercados de valores. Agrupa autoridades de supervisión y regulación de los mercados financieros a escala mundial, y su objetivo último es la armonización de las normas y de los procedimientos por los que se rigen dichos mercados. 
incremento de montos, número de emisiones, número de participantes, la aparición de nuevas operaciones, la innovación tecnológica y en general impulsar y mejorar el funcionamiento del mercado.

Los mercados de valores se basan en la confianza del público y en la disciplina de mercado, razón por la cual son vulnerables a comportamientos irracionales y pánico de los inversionistas. En esta medida es necesario que el interés estatal se oriente a prevenir el "efecto dominó", conforme al cual una situación de iliquidez o insolvencia de una entidad contagia al resto de los participantes del sistema y conduce a pérdidas para los inversionistas y para la economía en general.

Finalmente, si el objetivo de la intervención es la preservación del buen funcionamiento, la equidad, la transparencia, la disciplina y la integridad del mercado de valores y, en general, la confianza del público en el mismo, la actividad estatal debe concentrarse en la definición, detección y sanción de prácticas desleales de negociación y de las conductas contrarias al mercado.

\section{c. La regulación recae sobre los ámbitos objetivo y subjetivo del mercado}

En el ámbito subjetivo, esto es, en relación con los sujetos que intervienen en el mercado, el Estado colombiano ha orientado su actividad reguladora a reconocer los actores que participan en el mercado; fijar reglas para su constitución, organización interna, funcionamiento y extinción y a otorgarles habilitación para desarrollar su actividad. Expresamente reconoce como actores del mercado a emisores de valores, bolsas de valores, intermediarios de valore ${ }^{20}$, cámara de riesgo central de contraparte, depósitos centralizados de valores, sociedades calificadoras de valores y emisores, inversionistas, proveedores de infraestructura ${ }^{21}$, Superintendencia Financiera de Colombia y organismo autorregulador.

El ámbito objetivo está relacionado con las distintas actividades que pueden realizarse en el mercado respecto a derechos de naturaleza negociable que hacen parte de una emisión y que tiene por objeto o efecto la captación de recursos del público, denominados "valores".

Las actividades que son objeto de intervención son la emisión; la oferta pública para adquisición y venta de valores; la intermediación de valores; la administración

20 Esta expresión incluye sociedades comisionistas de valores, sociedades fiduciarias, sociedades administradoras de inversión, sociedades administradoras de fondos de pensiones y cesantías, entidades bancarias, compañías de financiamiento comercial, corporaciones financieras y aseguradoras.

21 Bajo esta denominación se incluyen los agentes a través de los cuales se realiza o facilita la intermediación de valores. Dentro de ello se encuentran: bolsa de valores, bolsas de bienes y productos agropecuarios y agroindustriales y de otros commodities; cámaras de riesgo central de contraparte; sociedades administradoras de sistemas de negociación y registro de operaciones y depósitos centrales de valores. 
de fondos de valores, fondos de inversión, fondos mutuos de inversión, fondos comunes ordinarios y fondos comunes especiales; el depósito y la administración de valores; la administración de sistemas de negociación o de registro de valores, futuros, opciones y demás derivados; la compensación y liquidación de valores; la calificación de riesgos; la autorregulación; creación de valores a partir del mecanismo de titularización y el suministro de información al mercado de valores.

Como instrumentos de apoyo a las actividades, la regulación ha creado figuras contractuales que sólo pueden tener lugar en este mercado. Tales figuras son contratos sobre índices ${ }^{22}$, operaciones de ventas en $\operatorname{corto}^{23}$, contrato de liquidez ${ }^{24}$ y contratos de reporto u operaciones repo ${ }^{25}$.

\section{d. Existe un régimen sancionatorio especial}

Las actividades desarrolladas por los sujetos están sometidas a un régimen sancionatorio tres áreas: penal, administrativa y disciplinaria.

La manipulación fraudulenta de especies inscritas en el registro nacional de valores y emisores es considerada como delito. En él incurre quien realice transacciones, con la intención de producir una apariencia de mayor liquidez respecto a determinada acción, valor o instrumento inscrito en el registro nacional de valores y emisores o quien realice maniobras fraudulentas con la intención de alterar la cotización de los $\operatorname{mismos}^{26}$.

Desde el punto de vista administrativo, corresponde a la Superintendencia Financiera de Colombia imponer sanciones a quienes desobedezcan sus decisiones; a quienes violen las normas que regulen el mercado de valores relacionadas con los ámbitos objetivo y subjetivo y a quienes incurran en alguna conducta prevista como infracción administrativa ${ }^{27}$. Las sanciones consisten en amonestación, multa a favor del tesoro nacional, suspensión o inhabilidad hasta por cinco años para realizar funciones de administración, dirección o control de las entidades sometidas a inspección y vigilancia permanente de la Superintendencia Financiera; remoción de quienes ejercen funciones de administración, dirección o control o del revisor fiscal y suspensión de la inscripción en el registro nacional de valores y emisores.

22 Artículos 1.6.1.1. a 1.6.1.6. de la Resolución 400 de 1995 de la Superintendencia de Valores hoy Superintendencia financiera.

23 Artículo 2.2.16.1 de la Resolución 400 de 1995 de la Superintendencia de Valores hoy Superintendencia financiera.

24 Artículos 2.2.19.1 a 2.2.19.7 Resolución 400 de 1995 Superintendencia de valores hoy Superintendencia Financiera de Colombia.

25 Decreto 4432 de 2006

26 Esa conducta es sancionada con prisión de dos a seis años y multa hasta de cincuenta mil salarios mínimos legales mensuales. Código Penal Colombiano artículo 317

27 El régimen sancionatorio administrativo está contenido en artículos 49 a 62 de la Ley 964 de 2005. Las conductas que son infracciones administrativas son las señaladas en el artículo 50 de esta ley. 
Enasuntos disciplinarios es el Autorregulador del Mercado de Valores el organismo competente para determinar la responsabilidad que exista por incumplimiento de normas del mercado valores, de los reglamentos de autorregulación y de los reglamentos de las bolsas de valores. Esta facultad disciplinaria la ejerce frente a los intermediarios de valores que voluntariamente se han sometido al autorregulador.

\section{e. Regula la información como pilar fundamental del mercado de valores}

Crea en el Derecho colombiano el Sistema Integral de Información del Mercado de Valores (SIMEV), como un conjunto de recursos humanos, técnicos y de gestión, administrado por la Superintendencia Financiera de Colombia para permitir y facilitar el suministro de información al mercado.

El sistema está integrado por el Registro Nacional de Valores y Emisores (RNVE), el Registro Nacional de Agentes del Mercado de Valores (RNAMV) y el Registro Nacional de Profesionales del Mercado de Valores (RNPMV).

El Registro Nacional de Valores y Emisores tiene por objeto inscribir las clases y tipos de valores, así como los emisores de los mismos y las emisiones que estos efectúen y certificar lo relacionado con la inscripción de dichos emisores clases y tipos de valores. La inscripción en este registro es requisito para los emisores que deseen realizar una oferta pública de sus valores o que los mismos se negocien en un sistema de negociación.

El Registro Nacional de Agentes del Mercado de Valores suministra información sobre las bolsas de valores, bolsas de bienes y productos agropecuarios y agroindustriales y sus miembros, las bolsas de futuros y opciones y sus miembros, sociedades que realicen compensación y liquidación de valores, contratos de futuros, opciones y otros; las sociedades comisionistas de bolsa, los comisionistas independientes de valores, las sociedades administradoras de fondos de inversión, las sociedades administradoras de depósitos centralizados de valores, las sociedades calificadoras de valores, las sociedades titularizadoras, los fondos mutuos de inversión que a 31 de Diciembre de cada año, registren activos iguales o superiores a 4000 smlmv a la fecha de corte, los fondos de garantía que se constituyan en el mercado público de valores, las sociedades administradoras de sistemas de negociación de valores, las cámaras de riesgo central de contraparte, las entidades que administren sistemas de negociación y registro de divisas y las sociedades administradoras de sistemas de compensación y liquidación de divisas. La inscripción en este registro es condición para actuar en el mercado de valores.

Las personas que realicen actividades de intermediación en el mercado de valores (comisionistas, corredores de valores, quienes hagan cuenta propia en condiciones habituales, fondos colectivos de inversión, las fiduciarias en desarrollo de fiducia de inversión y las entidades públicas), los fondos mutuos de inversión sometidos a control de la Superintendencia Financiera de Colombia, también deben estar inscritas en el Registro Nacional de Agentes del Mercado de Valores 
El Registro Nacional de Profesionales del Mercado de Valores se encarga de inscribir personas naturales que cumplan cualquiera de las siguientes condiciones: que estén al servicio de un intermediario de valores y se encarguen de estructurar operaciones de intermediación; dirijan o ejecuten directamente operaciones de intermediación en el mercado de valores; administren o gestionen directamente fondos de valores, fondos de inversión, fondos comunes ordinarios y especiales; administren o gestionen directamente fondos mutuos de inversión sometidos a la inspección y vigilancia permanente de la Superintendencia Financiera; promuevan o promocionen la realización de operaciones de intermediación en el mercado de valores. La inscripción en este registro es condición para actuar en el mercado de valores así como en el de bienes y productos agropecuarios, agroindustriales o de otros commodities.

f. Las controversias que se den entre los agentes del mercado las dirime la justicia ordinaria.

La intervención estatal no ha diseñado instrumentos ni autoridades especiales para dirimir conflictos que se originen en las distintas relaciones que surgen en el mercado de valores. Cada situación se analiza a la luz de la responsabilidad civil contractual o extracontractual.

Existe una acción denominada "acción de clase" que pueden ejercitar los perjudicados contra la persona que actúe en el mercado de valores que haga uso de información privilegiada ${ }^{28}$ o que incumpla con el deber de suministrar información oportuna. Se trata de una acción judicial de responsabilidad civil.

Existe una relación temática entre las razones que justifican la intervención del Estado y las características reseñadas que permite aceptar que el modelo de intervención adoptado no atiende exclusivamente a razones económicas y financieras. Esta relación se presenta a continuación.

La intervención para remediar o corregir fallas de mercado materializa en primer lugar en incluir la protección a los derechos de los inversionistas como objetivo de intervención del Estado colombiano en el mercado de valores y en segundo lugar, en considerar la información como el medio más eficiente para proteger los intereses del los inversionistas y del mercado.

La falla del mercado conocida como asimetría de información busca ser corregida mediante la intervención. El Estado colombiano garantiza información oportuna, completa y exacta. La oportunidad se refleja en que la información se suministre al mercado y esté disponible antes de adoptar la decisión de invertir, de tal forma que el inversionista disponga del tiempo necesario para asimilarla, ya por que cuenta con

28 Es privilegiada la información concreta que no ha sido dada a conocer al público que un inversionista medianamente diligente y prudente habría tenido en cuenta al negociar los valores 
elementos de juicio suficientes para hacerlo o por que acuda a asesores financieros para valorarla.

Información completa hace referencia al cumplimiento de los requisitos mínimos que señale el ordenamiento jurídico. La intervención estatal facilita la labor de verificación del cumplimiento de los requisitos, para tal fin atribuye a la Superintendencia Financiera de Colombia verificar el cumplimiento de tales mínimos.

No hay en el ordenamiento jurídico colombiano garantía de "exactitud" de la información. La información suministrada tiende a limitarse al sector de especialistas en mercado de valores, quienes cuentan con el conocimiento y la experiencia necesarios para interpretarla y realizar predicciones sobre las consecuencias de acontecimientos pasados, presentes o futuros, o a confirmar o corregir expectativas.

Se admite que los procesos informativos son imperfectos ya que el acceso a la información es diferenciado y está determinado tanto por la capacidad económica de los destinatarios de la información como por las posibilidades de uso de la información por parte de los agentes.

Desde el punto de vista financiero la intervención estatal del Estado colombiano en el mercado de valores no ha sido diseñada para extinguir los riesgos de crédito, de mercado, de liquidez, riesgo país y riesgo soberano. Los esfuerzos se orientan a contribuir a la administración del riesgo operativo.

El Estado garantiza negociar con operadores autorizados y vigilados por él. El ingreso al mercado con autorización estatal, la necesidad de estar inscritos en el SIMEV y la existencia de un régimen sancionatorio especial ponen de presente que el Estado colombiano centra atención solo en el riesgo operativo. Implícitamente el modelo de regulación convoca al inversionista a identificar riesgos que están implícitos en el mercado que no pueden administrarse con instrumentos, técnicas o herramientas legales; esto significa que hay riesgos que el inversionista debe conocer y asumir no obstante la intervención estatal en el mercado.

La forma y la dinámica que se utiliza para intervenir en el mercado de manera expresa, no reconoce razones financieras ni económicas. Adopta el "interés público" como criterio general de regulación que se concreta en la constante intervención del Estado en los ámbitos objetivo y subjetivo del mercado donde se realizan actividades privadas cuyo contenido comporta, por mandato legal, un interés público.

Un observador de fenómenos económicos entiende que afirmar que una actividad es de interés público para justificar la intervención, significa que el Estado reconoce que en el mercado de valores existe un conjunto de intereses individuales compartidos y coincidentes que no pueden interactuar libremente y que requieren la constante intervención estatal.

La intervención del Estado colombiano en el mercado de valores no responde a razones económicas o financieras ni a la suma de todos los intereses particulares sino a razones políticas que permiten atribuir al Derecho funciones de fomento y 
promoción de ciertos valores o intereses fijados unilateralmente por el Estado que no necesariamente coinciden con valores u objetivos del mercado.

Bajo la directriz del interés público, como herramienta política, el mercado de valores colombiano ha de entender que el papel del Estado no es la satisfacción de las necesidades de los emisores, inversionistas, bolsas de valores e intermediarios del mercado. La intervención estatal busca "asegurar las condiciones en las que individuos y grupos menores tengan oportunidades favorables de atender mutuamente sus respectivas necesidades" (Hayek, 2006, 188)

\section{CONCLUSIONES}

1. La intervención del Estado colombiano en el mercado de valores incluye los mercados bursátil y extrabursátil; primario y secundario; renta fija y renta variable.

2. La intervención se manifiesta mediante la regulación y supervisión. La primera es ejercida por el Gobierno nacional según los objetivos y criterios que señale el Congreso de la República en la ley marco y la segunda por la Superintendencia Financiera de Colombia. Una y otra incluye los ámbitos objetivo y subjetivo del mercado.

3. De la misma forma como no hay un mercado perfecto la regulación perfecta es inalcanzable. El regulador también tiene asimetrías de información y está expuesto a responder a intereses económicos de algunos regulados. Bajo este supuesto basta con que el Estado intervenga en el mercado para potenciarlo y para permitir su funcionamiento.

4. La intervención del Estado colombiano en el mercado de valores no se justifica de manera aislada por razones económicas, jurídicas o financieras. Es un marco de referencia para el desarrollo de actividades o negocios sobre valores que intenta resolver conflictos y contradicciones; opera como mecanismo de control social; limita acciones maximizadoras de los agentes en el mercado y hace posible que el mercado viva su propia dinámica.

5. La intervención del Estado en el mercado de valores abre paso a la construcción de una de las manifestaciones del Derecho Económico conocida como "Derecho del Mercado de Valores", disciplina que deja de tener las características de un sistema normativo formal compuesto por reglas cuyo cometido es orientar la conducta de un grupo social, por el contrario, contiene normas encaminadas a conseguir objetivos y realizar fines trazados por el Estado para permitir el funcionamiento del mercado. 


\section{REFERENCIAS}

Bodie, Zvie y otros (2004). Principios de Inversiones. $5^{\text {a }}$ Edición. Mc Graw Hill Books, España

Cachón, J. (1992). Derecho del Mercado de Valores Tomo I. Editorial Dykinson, Madrid,

Carmichael, Jeffrey y Michael Pomerleano (2005). Desarrollo y Regulación de Instituciones Financieras no Bancarias. Banco Mundial en Coedición con Mayol Ediciones S.A, Bogotá.

Fabozzi, Frank (1996). Mercados e Instituciones Financieras. Prentice Hall.

Formariz, Francisco (2001). Las Bolsas: organización y funcionamiento, en Curso de bolsa y mercados financieros. Publicación del Instituto Español de Analistas Financieros (Director José L. Sánchez Fernández de Valderrama), Ariel Economía,

García, M. (2002). La Importancia de la comunicación pública societaria en Revista Iberoamericana de Mercados de Valores. Marzo. No 5.

Hayek, Friederich A. (2006). Derecho, legislación y libertad. Unión editorial, Madrid.

Madura, Jeff (2001). Mercados e Instituciones Financieras. $5^{\text {a }}$ Edición. Thompson Learning. México.

Martínez, N. (2004). Cátedra de Derecho Bancario, $2^{\mathrm{a}}$ Edición, Legis, Bogotá.

Pindyck, Robert y otros (2003). Microeconomía. 5a Edición, Prentice Hall, Madrid.

Stiglitz, J. (2003). Los felices 90. La semilla de la destrucción. Rosés S.A, Madrid.

Smith, A. (1997). Una Investigación sobre la naturaleza y causa de la riqueza de las naciones Fondo de Cultura Económica, novena reimpresión, México.

Villariño, Á. (2001). Turbulencias financieras y riesgos de mercado. Pearson Educación S.A, Madrid.

Zegarra, D. (2005). Servicio Público y Regulación. Marco Institucional de las Telecomunicaciones en el Perú. Palestra Editores SAC, $1^{\text {a }}$ edición, Lima.

\section{Legislación}

Constitución Política de Colombia

Ley 964 de 2005

Decreto 1121 de 2005

Decreto 4327 de 2005

Decreto 3139 de 2006

Decreto 4432 de 2006

Resolución 400 de 1995 Superintendencia de Valores hoy Superintendencia Financiera de Colombia. 